\title{
Cheek Plumper with a Salivary Reservoir: An Esthetic and Functional Treatment Option for a Xerostomic Patient with Sunken Cheeks
}

\author{
Godwin Da Costa*, Meena Aras, Vidya Chitre, Praveen Rajagopal and Aradhna Nagarsekar
}

Department of Prosthodontics, Goa Dental College and Hospital, Bambolim Goa, Panaji, Goa, India

\begin{abstract}
Sensation of dry mouth or xerostomia results from a variety of factors including radiotherapy (RT) given for the treatment of oral carcinomas. A reservoir space for artificial salivary substitutes in the complete and partial dentures in cases of severe xerostomia ensure a steady continuous delivery of saliva. This case report describes the rehabilitation of a 65 year old totally edentulous patient with xerostomia and sunken cheeks using a novel simplified technique of fabricating a hollow cheek plumper with a salivary reservoir.
\end{abstract}

Keywords: Xerostomia; Hollow denture; Cheek plumper; Salivary reservoir

\section{Introduction}

Xerostomia is defined as dry mouth resulting from reduced or absent salivary flow. It presents as a symptom in Sjogrens syndrome, endocrine disorders or as a side effect of cancer therapy (RT as well as chemotherapy) and medications (Antidepressants tranquilisers diuretics and anti histaminics) [1]. It is usually accompanied with a constant sore throat, difficulty in speaking and swallowing and hoarseness of the voice [2]. Dentures that ordinarily rehabilitate the edentulous patient are poorly tolerated in such patients since the absence of saliva. Saliva is ordinarily present as a thin film between dentures and the oral mucosa. Lack of saliva may cause decreased retention of the prosthesis as well as increased chances of inflammation and ulceration in the oral cavity.

Edentulous patients suffering from xerostomia may also present with findings such as slumping of cheeks due to loss of teeth and subsequent resorption of bone especially in the premolar and molar region. Proper extension of the denture flange can help restore facial contours.

This report describes the rehabilitation of a xerostomic patient with hollow cheeks using a simplified technique of constructing a hollow cheek plumper with a salivary reservoir.

\section{Case Report}

A 65 year old male patient reported to the Department of Prosthodontics with the chief complaint of missing teeth and sought replacement (Figure 1). The patient suffered from cancer of the vocal cord about 5 years ago. He was successfully operated for the same and radiation therapy was used during the treatment prior to which he had to undergo total extraction of teeth. The patient also reported the frequent occurrence of oral ulcers and pain on swallowing. He gave no history of previous denture use. On examination, the erythema and inflammation could be well appreciated in the oral cavity. Extraorally, slumping of the left cheek was visible. The history and examination indicated a radiation induced xerostomia. After discussion and planning, it was decided that the patient should be given a cheek plumper with an artificial salivary substitute to improve his overall appearance and aid him in his daily oral activities. A hollow cheek plumper was made to act as an artificial salivary reservoir (Figure 2).

\section{Clinical Procedure}

Primary impressions were made in impression compound ( $\mathrm{Y}$ Dents, Delhi, India) while final impressions were made in light body elastomeric impression material. In the try-in appointment the upper and lower waxed dentures were tried first for occlusion, appearance and phonetics. Wax (Hindustan Dental Products Hyderabad India) was then added in the premolar and molar region on the buccal side of the upper denture to restore the facial contour and give the patient an esthetic, fuller and symmetrical appearance (Figure 3 ). The denture was further evaluated for retention and stability. The maxillary denture was invested in dental plaster (Kaldent kalabhai India) and subsequently dewaxed (Figure 4).

High viscosity C- silicone elastomeric material (Zeta plus Zhermack co) was mixed and placed in the cavity formed by the waxed cheek plumper and trial closure of the flask was done using a cellophane sheet after placing heat cure acrylic resin into both the flask and its counter half (Figure 5). After the trial closure the flask was opened and proper placement of the putty was confirmed (Figure 6). Putty was removed

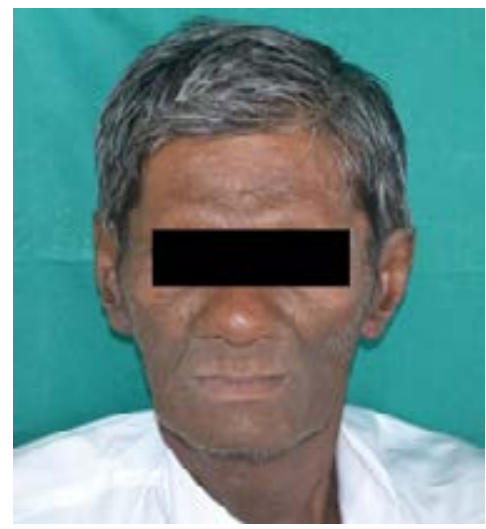

Figure 1: Pre operative photo.

*Corresponding author: Godwin Da Costa, Department of Prosthodontics, Goa Dental College and Hospital, bambolim goa, Panaji, Goa, 403202, India, Tel: 919764597543; E-mail: drgodwindacosta@gmail.com

Received February 22, 2015; Accepted March 19, 2015; Published March 23 2015

Citation: Da Costa G, Aras M, Chitre V, Rajagopal P, Nagarsekar A (2015) Cheek Plumper with a Salivary Reservoir: An Esthetic and Functional Treatment Option for a Xerostomic Patient with Sunken Cheeks. Dentistry 5: 293. doi:10.4172/21611122.1000293

Copyright: ( 2015 Da Costa G, et al. This is an open-access article distributed under the terms of the Creative Commons Attribution License, which permits unrestricted use, distribution, and reproduction in any medium, provided the original author and source are credited. 


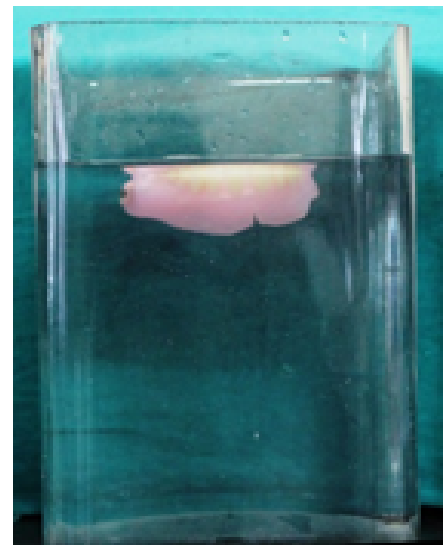

Figure 2: Hollow denture.

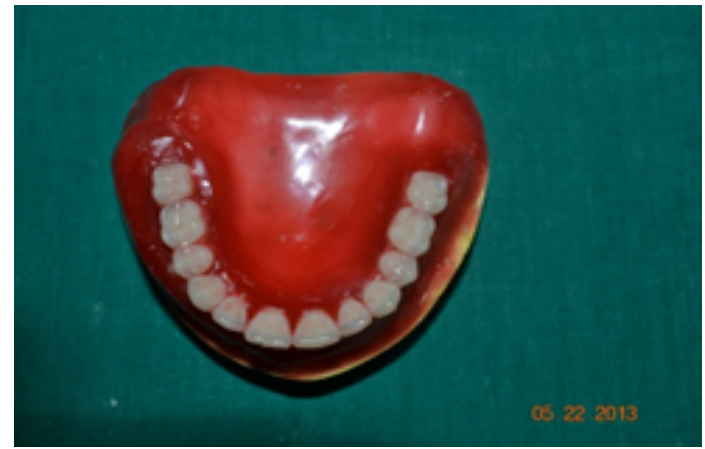

Figure 3: Waxed maxillary denture.

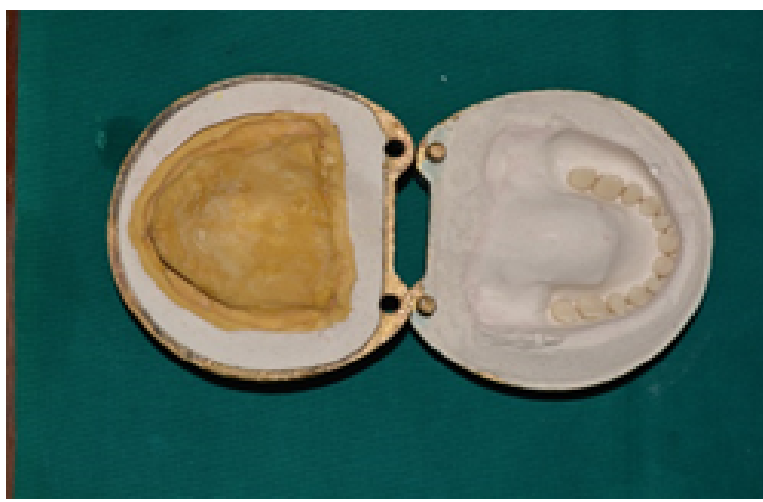

Figure 4: Flask and its counter after dewaxing.

and the space created was filled with salt and the flask was closed (Figure 7). The denture was acrylised using the short curing cycle.

After the denture was retrieved, two holes were made, one in the left molar region on the buccal aspect for the inlet of the artificial saliva and the other on the opposite side in the molar region on the palatal aspect for the outlet of saliva. Hot water was flushed in using a syringe to dissolve and remove the salt. The space created was measured using a syringe and water determined to be $2 \mathrm{ml}$. The inlet hole was closed using a shortened brass box screw (Anchor India) (Figure 8) to provide a tight seal and no leakage of saliva, also permitting the patient to open the hole to refill the saliva (Figure 9). At the outlet hole a rubber stopper from an endodontic file was placed to regulate the flow of the saliva. The brass screw and the rubber stopper were placed using autopolymerising acrlic resin.

E-saliva (Entod pharmaceuticals Mumbai) was used as a salivary substitute. The patient was instructed in denture care and to refill the denture twice a day after meals. The lower denture was fabricated in a conventional manner.

Recall appointments were scheduled after $24 \mathrm{~h}, 1$ week, 4 weeks and every 6 months. At recall appointments, good retention was observed and relief from the symptoms of dry mouth and improvement in dietary intake was reported by patient (Figure 10).

\section{Discussion}

Xerostomia can be managed to an extent by increasing the frequency of water intake, improving dietary habits by including more citrus fruits in the diet. Salivary stimulants such as sugar free chewing gums or lozenges also help stimulate and increase the salivary output [3]. Several cases have been documented where xerostomic edentulous

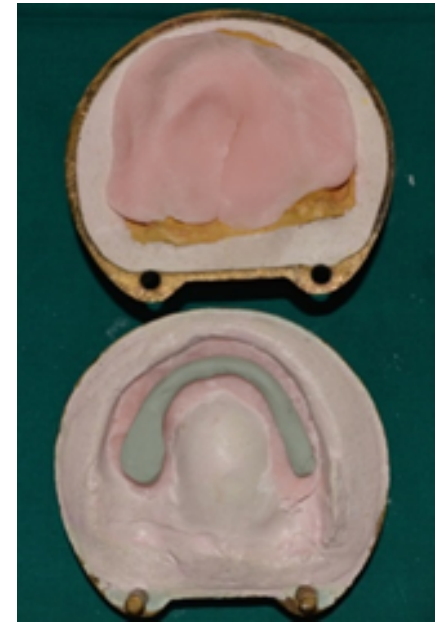

Figure 5: Placement of putty and trial closure of flask.

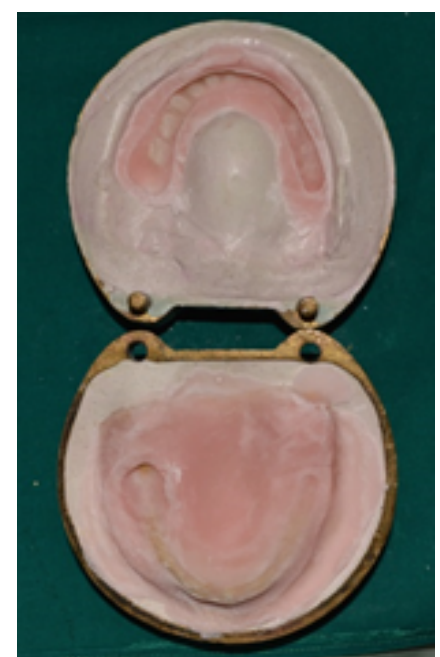

Figure 6: Evaluation of hollow space created. 


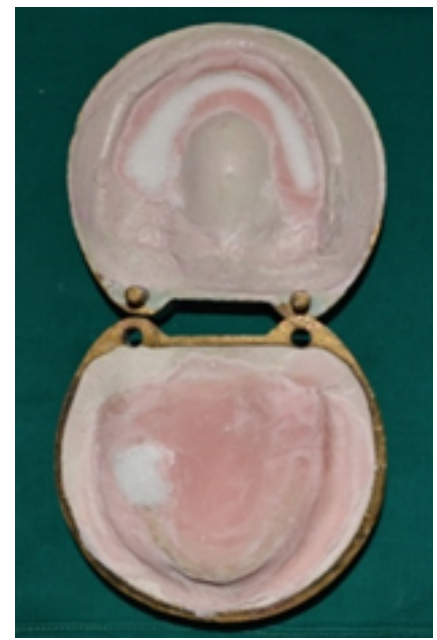

Figure 7: Placement of salt prior to final closure of flask.

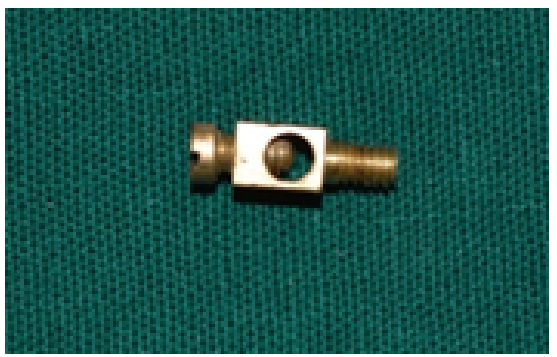

Figure 8: Brass box screw.

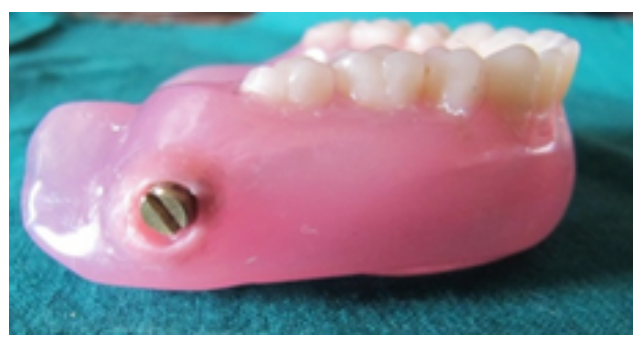

Figure 9: Placement of screw in the inlet hole of the denture.

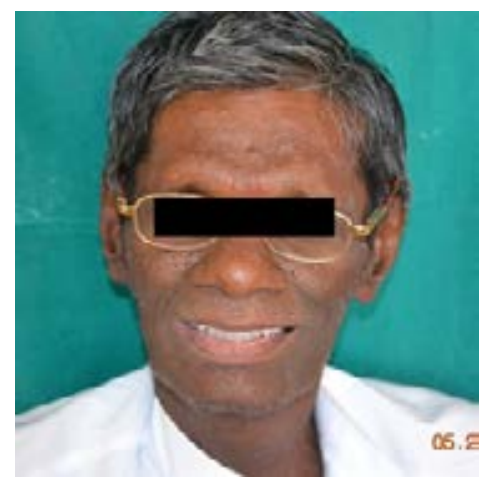

Figure 10: Post-operative photo. patients have been treated with salivary substitutes incorporated into the maxillary or mandibular dentures $[4,5]$.

Sunken cheeks are very common in the completely edentulous patient due to loss of support. A conventional cheek plumper is a part of the complete maxillary denture prosthesis forming single unit prosthesis with extension on either side in the region of the polished buccal surfaces of the denture which are continuous with the rest of the denture [6,7]. The conventional cheek plumper if not made hollow could add excessive weight to the upper denture thus compromising the retention of the prosthesis. Hence it was decided to fabricate a hollow cheek plumper.

Vinylpolysiloxane (VPS) putty does not adhere to acrylic resin and its use for fabrication of hollow prostheses due to its stability and ability to be carved is well documented [8]. However, retrieval of the putty from the hollow space has been proven difficult. In the lost salt technique the hollow space collapses or decreases due to the force exerted during the flask closure [9]. The trial closure done in this technique with the putty index creates space for the salt and hence prevents extra pressure on it during final closure.

A salivary reservoir was incorporated into the denture in an attempt to improve the xerostomic condition of the patient by utilizing the space afforded by the bulk of the cheek plumper thus simultaneously enabling comfort and esthetics. Care was taken to avoid impingement of buccal extension on the masseter muscle and coronoid process of the mandible so as to avoid destabilisation. Since the patient had adequate mouth opening the increased medio-lateral width of the denture did not result in difficulty in insertion of the denture into the mouth.

\section{Conclusion}

The salt and putty technique used to fabricate maxillary complete denture with hollow cheek plumper (Figure 8) was found to be effective with good patient compliance. The technique combines the advantages of both the salt and the putty techniques resulting in an esthetic, lighter denture.

\section{References}

1. Mendoza AR, Tomlinson MJ (2003) The split denture: a new technique for artificial saliva reservoirs in mandibular dentures. Aust Dent J 48: 190-194.

2. Diaz-Arnold AM, Marek CA (2002) The impact of saliva on patient care: A literature review. J Prosthet Dent 88: 337-343.

3. Upadhyay SR, Kumar L, Rao J (2012) Fabrication of a functional palatal saliva reservoir by using a resilient liner during processing of a complete denture. $J$ Prosthet Dent 108: 332-335.

4. Debnath N, Gupta R, Devi AS, Meenakshi A, Ramkumar K (2013) Prosthodontic Rehabilitation of an Ectodermal Dysplasia Patient with Artificial Saliva Reservoir in Complete Denture. Int J Prosthodont Restor Dent 3: 37-41.

5. Arora V, Kumar D, Legha VS, Kumar KA (2014) Management of Xerostomia Patient with Salivary Reservoir designed in Upper Complete Denture and Lower Cast Partial Denture. Journal of Contemporary Dentistry 4: 56-59.

6. Lazzari JB (1955) Intraoral splint for support of the lip in Bell's palsy. The Journal of Prosthetic Dentistry. 5: 579-81.

7. Larsen SJ, Carter JF, Abrahamian HA (1976) Prosthetic support for unilateral facial paralysis. J Prosthet Dent 35: 192-201.

8. O'Sullivan M, Hansen N, Cronin RJ, Cagna DR (2004) The hollow maxillary complete denture: a modified technique. J Prosthet Dent 91: 591-594.

9. Aggarwal H, Jurel SK, Singh RD, Chand P, Kumar P (2012) Lost salt technique for severely resorbed alveolar ridges: An innovative approach. Contemp Clin Dent 3: 352-355. 